\title{
Prevalence of Various Cancer-Related Risk Factors among the Forcibly Displaced Myanmar National Community, the Rohingya, in Bangladesh: A Preliminary Assessment
}

\author{
Rumana Dowla ${ }^{1}$, Annekathryn Goodman ${ }^{2}$, Sadia Akter ${ }^{3}$ \\ ${ }^{1}$ Bangladesh Palliative and Supportive Care Foundation, Bangabandhu Sheikh Mujib Medical University and Hospital (BSMMU), \\ Dhaka, Bangladesh \\ ${ }^{2}$ Division Gynecologic Oncology, Harvard Medical School, Massachusetts General Hospital, Boston, MA, USA \\ ${ }^{3}$ Bangladesh Palliative and Supportive Foundation (BPSCF), Dhaka, Bangladesh \\ Email: ^rumanadowla@gmail.com, agoodman@mgh.harvard.edu, sadia.shammi91@gmail.com
}

How to cite this paper: Dowla, R., Goodman, A. and Akter, S. (2020) Prevalence of Various Cancer-Related Risk Factors among the Forcibly Displaced Myanmar National Community, the Rohingya, in Bangladesh: A Preliminary Assessment. Journal of Cancer Therapy, 11, 251-264.

https://doi.org/10.4236/jct.2020.115021

Received: April 12, 2020

Accepted: May 3, 2020

Published: May 6, 2020

Copyright $\odot 2020$ by author(s) and Scientific Research Publishing Inc. This work is licensed under the Creative Commons Attribution International License (CC BY 4.0).

http://creativecommons.org/licenses/by/4.0/

(c) (i) Open Access

\begin{abstract}
Background: Large numbers of Forcibly Displaced Myanmar Nationals (FDMN), also called the Rohingya community, in Bangladesh face chronic life-threatening illnesses. Symptoms concerning for a cancer diagnosis are not easily evaluated and treated by healthcare systems available to this population. We conducted a rapid needs assessment of cancer screening and pain and palliative care with the goal of identifying the prevalence of cancer risk factors among the Rohingya who attended local health facilities. Methods: A cross-sectional study was conducted in the Kutupalong camp of Ukhiya, Cox's Bazar among the Rohingya community. Data were collected through purposive sampling. Face-to-face interviews were done using a structured questionnaire. Statistics were analyzed by using IBM SPSS 23. Results: Out of 85 participants, 75 were female and 10 were male. 70 (82.4\%) were uneducated (defined as lacking any formal institutional education), 10 (11.8\%) people completed the primary level education and only 5 (5.9\%) people received secondary level education. There were many participants with pulmonary disease with 35 (41.2\%) people endorsing a history of asthma, bronchitis, and/or tuberculosis. There was a lack of female menstrual sanitation and hygiene with only 25 (29.4\%) patients using sanitary napkins, that were donated by Non Government Organizations. Only $5.9 \%$ of the women had received any form of cervical cancer screening. Conclusion: This study identifies risk factors associated with cancers and life-limiting diseases among the FDMN Rohingya refugees in Bangladesh. It is necessary to develop targeted education, cancer screening and cancer awareness programs for this population.
\end{abstract}




\section{Keywords}

Cancer, Risk Factors for Cancer, Life-Limiting Illness, Palliative Care, FDMN (Forcibly Displaced Myanmar National), Rohingya, Menstrual Hygiene, Pulmonary Disease, Cox's Bazar, Bangladesh

\section{Introduction}

In 2017 due to an escalation of violence against the Rohingya Communities of the Rakhine State, close to 700,000 people fled across the border to Bangladesh without supplies, food and non-food items, or medicine [1]. There are five domains of survival for refugees and migrants: access to healthcare, food and nutrition, shelter, water and sanitation, and communication [2]. Communicable and vaccine preventable diseases are an immediate concern in this largely unvaccinated population [3]. Basic medical care has been provided through the health sector, which is coordinated under the Civil Surgeon's Office of Cox's Bazar, the Directorate General Health Services, and the World Health Organization [4]. Organization of health outreach and communication of services to communities goes through the refugee camp social structure which uses a Majhi, a leader who is chosen by the community to communicate with the host community [5]. Under the Majhi, there are several deputy Majhis who speak for and represent a group of families.

The forcibly displaced Myanmar nationals (FDMN) or Rohingya refugees in Bangladesh face many obstacles to preventive health care. Identification of cancer risk factors and the detection and treatment of life-limiting diseases are neglected areas of health intervention among the FDMN Rohingya refugees. Rohingya people have large families and a high level of illiteracy. Seventy-six percent of Rohingya adults had no education and within the refugee camps; fifty-two percent of children did not attend school. Almost $80 \%$ of household reported no current income [6]. To better understand the challenges and health concerns for this stressed and deprived community and develop effective interventions, it is necessary to assess incidence and prevalence of risk factors for life-limiting illnesses.

Risk factors for life-limiting illness and cancer in particular can be related to genetic or environmental factors. Additional risk factors for poor outcomes include lack of access to health services including the availability of well established cancer screening programs, inability to make one's own medical decisions based on the family or community hierarchy and poor health literacy. Specific individual and community risks for the development of cancers and life-limiting illnesses include poor personal and community hygiene causing the spread of infectious diseases and the risk of malnutrition, which reduces individual immunity to illnesses. Additional personal risks include exposure to carcinogenic agents such as tobacco and alcohol; cancer associated infectious diseases such as 
high-risk human papillomavirus infections (HPV), hepatitis C, human immunodeficiency virus (HIV) and well as malaria, dengue, and many childhood infections such as measles. There are no studies among the Rohingya population about the prevalence of cancer promoting risk factors.

This study measures prevalence of cancer-related risk factors of families of FDMN Rohingyas and identifies currently available interventions. Understanding the levels of cancer-related and health-related knowledge will enable a healthcare program to be tailored more appropriately to the needs of the population. Educational outreach among the population and the caregivers of the ill can be given to improve health outcomes.

\section{Methods}

\subsection{Study Site and Population}

This study was conducted at Kutupalong camp 2 in Ukhiya, Cox's Bazar. All the patients were seen at the camp's two health facilities. Men and women who were able to consent and were between the ages of 18 years and 65 years were included in the study. Exclusion criteria were as follows: those who were unable to consent and people who had incapacitating health issues or mental disability where it was felt they could not give informed consent. Participants gave informed consent. Face-to-face interviews were conducted by the authors for 30 minutes in Bangla with the help of a Rohingya language interpreter. Rohingya, the language spoken by the Rohingya people of the Rakine State, is an eastern Indo-Aryan language coming from the Bengali-Assamese branch [7]. Table 1 shows the questions asked of all participants.

\subsection{Study Approach}

A descriptive qualitative approach was used to understand the socio demographic aspects of the Rohingya population and of the local people residing in Ukhiya, Cox's Bazar. On $2^{\text {nd }} \& 3^{\text {rd }}$ of July 2019 we visited the Rohingya camp 2 Kutupalong, where we interviewed 85 participants coming to the two different health facilities. Our team also included an educational session on Self Breast Examination (SBE). This was a qualitative study and there was no sample size analysis.

\subsection{Study Design and Period}

This study was conducted by a cross-sectional design and was conducted from April 2019 to August 2019. A structured questionnaire was used to collect information from the study population.

\subsection{Definitions for Scoring Pain and Cancer Risk Factors}

For evaluation of pain, the numeric pain rating scale (NRS) was used where 0 means no pain, 1 - 3 mild pain, 4 - 6 moderate pain, 7 - 10 severe pain [8]. Cancer risk factors for oral, lung, cervical, and breast cancers were assessed using 
Table 1. Questionnaire used on 85 Rohingya Participants.

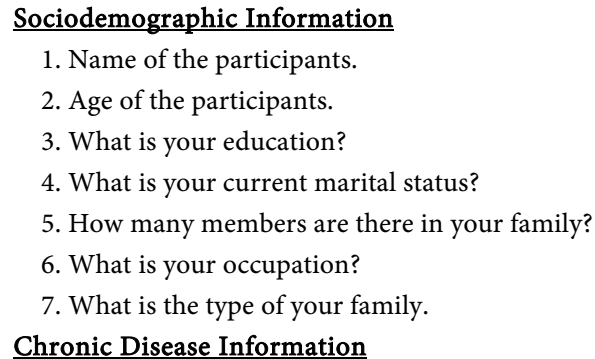

Chronic Disease Information

1. Is there anyone suffering from cancer in your family?

2. Do you have anyone in your family suffering from diabetes/hypertension/kidney disease/heart disease?

3. Is there anyone in your family who is bed ridden?

4. If yes, how old is he/she?

5. What is the reason of illness?

6. Is there anyone in your family who is more than 70 years old?

7. Do you have anyone in your family who has dementia?

\section{Breast Cancer Related Information}

1. Are you currently pregnant?

2. Have you ever experienced abortion?

3. Have you ever experienced miscarriage?

4. Did you breast feed your children.

5. Have you ever used contraceptive.

6 . How old were you when your menstrual periods have stopped?

7. Have you ever heard of breast cancer?

8. Is there anyone in your family suffering from breast cancer?

9. Do you know how to do self-examination for breast cancer?

10. Have you ever felt any lump in your breast?

\section{Lung Cancer Related Information}

1. Do you smoke?

2. If yes, how many in a day?

3. When did you start smoking?

4. Have you ever stopped smoking for more than 6 months?

5. Have you ever heard of lung cancer?

6. Have you ever diagnosed with bronchitis/asthma/tuberculosis?

7. Are you taking any medicine currently?

\section{Cervical Cancer Related Information}

1. Have you heard of cervical cancer?

2. Did a health provider talk to you about cervical cancer?

3. Do you use sanitary napkins?

4. Have you ever heard of a vaccine to prevent cervical cancer?

5. Have you ever heard of a vaccine to prevent cervical cancer?

6. Have you ever undergone any of the examinations? -Pap smear, VIA.

7. If yes what was the result?

8. Have you ever heard about HPV?

\section{Oral and Facial Maxillary Cancer related Information}
1. Do you have a sharp tooth?
2. Have you ever felt pain or burning sensation inside mouth?
3. Have you ever experienced pain or swelling on neck?
4. Have you ever visited a dentist?
5. Do you chew betel nut/tobacco leaf/pan/masala?
6. Do you use any other kind of smoke?
7. Have you ever suffered from discharging pus/sinus/oozing from mouth? 
validated questionnaires [9] [10] [11].

\subsection{Sampling Technique}

Purposive sampling was done with the study population considering the feasibility of the study. Purposive sampling is a technique also known as judgmental, selective, or subjective sampling. It is a form of non-probability sampling in which researchers rely on their own judgment when choosing members of the population to participate in their study [12].

\subsection{Study Variables}

Cancer risk factors were considered as dependent variables and socio-demographic and education information were independent variables.

\subsection{Ethical Approval}

Approval was collected from the Refugee Relief and Repartition Commissioner Office. During data collection, informed written consent was collected from study participants. Prior permission was obtained from the Refugee Relief and Repatriation Commissioner. In addition, permission was received from the Director of Camp 2 and the Cox's Bazar health complex.

\subsection{Data Processing}

After developing questionnaire to check the reliability, the study tools were pre tested among the Rohingya refugees. Any issues of language, comprehension, and content found on the questionnaire were reviewed and corrected accordingly.

\subsection{Statistical Analysis}

Translation in Bangla and back translation was done to ensure the accuracy of data. Data were analyzed using IBM SPSS software version 23.

\section{Results}

Table 2 represents information on socio-demographic characteristics of the participants. A total of eight-five participants were interviewed at the health facilities. The average age of women was 25 years (range 18 to 65 years). The average age of men was 30 (range 18 to 50 years). Seventy-five (88.2\%) were female and ten $(11.8 \%)$ were male. Seventy $(82.4 \%)$ participants had not received any formal education, ten $(11.8 \%)$ participants had completed their primary level education and only five (5.9\%) participants had completed secondary school. All the women were housewives and all the men were unemployed within the refugee camp. Fifty (58.8\%) of the participants lived as nuclear families and 35 (41.2\%) had extended families. Table 3 summarizes the health literacy of the participants. Fifteen (17.6\%) people were familiar with lung cancer, twenty-five (29.4\%) people knew about breast cancer, ten (11.8\%) people had heard of cervical cancer, 
Table 2. Socio-demographic Profile of 85 Rohingya Participants in the Kutupalong Refugee camp in Ukhiya, Cox's Bazar

\begin{tabular}{ccc}
\hline Education level & Frequency & Percentage (\%) \\
Uneducated & 70 & 82.4 \\
Primary & 10 & 11.8 \\
Secondary & 5 & 5.9 \\
Occupation & & \\
Housewife & 75 & 88.2 \\
Unemployed & 10 & 11.8 \\
Family type & & \\
Nuclear family & 50 & 58.8 \\
Joint family & 35 & 41.2 \\
\hline
\end{tabular}

Table 3. Health literacy for cancer of 85 Rohingya Participants in the Kutupalong Refugee camp in Ukhiya, Cox's Bazar.

\begin{tabular}{ccc}
\hline $\begin{array}{c}\text { Familiarity with: } \\
\text { Lung Cancer }\end{array}$ & \# of Participants & Percentage (\%) \\
\hline Yes & 15 & 17.6 \\
No & 70 & 82.4 \\
Breast Cancer & 25 & 29.4 \\
Yes & 50 & 58.8 \\
No & & \\
Cervical Cancer & 10 & 11.8 \\
Yes & 60 & 88.3 \\
No & & \\
Oral Cancer & 5 & 5.9 \\
Yes & 80 & 94.1 \\
No & & \\
\hline
\end{tabular}

and five $(5.9 \%)$ were familiar with oral cancer.

Table 4 shows prevalence of cancer-related risk factors. The male participants endorsed smoking 20 - 25 cigarettes per day and had started smoking by ages 15 to 18 years. Most of the patients were unaware of lung cancer. The majority, sixty-five participants (76.5\%), chews betel quid nut and Jorda. Jorda is a burnt smokeless tobacco. Only five (5.9\%) people visited the dentist. Twenty $(23.5 \%)$ people suffered from oozing and pus in the mouth and twenty-five $(29.4 \%)$ of the participants had oral and tooth pain.

Only $29.4 \%$ of women used sanitary napkins and the remainder used dirty rags. Only five of the eight-five women (5.9\%) had received any form of cervical cancer screening. Twenty-three percent and almost six percent of women experienced miscarriage and/or abortions, respectively, in their lifetime. Thirty-five 
Table 4. Prevalence of cancer related risk factors of 85 Rohingya Participants in the Kutupalong Refugee camp in Ukhiya, Cox's Bazar

\begin{tabular}{|c|c|c|}
\hline \multicolumn{3}{|c|}{ Oral Cancer Related Risk Factors } \\
\hline Betel quid/Jorda consumption & \# of Participants & Percentage (\%) \\
\hline Yes & 65 & 76.5 \\
\hline No & 20 & 23.5 \\
\hline \multicolumn{3}{|l|}{$\underline{\text { Visit to dentist }}$} \\
\hline Yes & 5 & 5.9 \\
\hline No & 80 & 94.1 \\
\hline Pus/ sinus/oozing from mouth & $\underline{\text { Yes }}$ & $\underline{\text { No }}$ \\
\hline Yes & 20 & 23.5 \\
\hline No & 65 & 76.5 \\
\hline \multicolumn{3}{|l|}{ Cervical Cancer Related Risk Factors } \\
\hline \multicolumn{3}{|l|}{$\underline{\text { Sanitary napkin use }}$} \\
\hline Yes & 25 & 29.4 \\
\hline No & 25 & 29.4 \\
\hline Sometimes (supplied by NGOs) & 20 & 23.5 \\
\hline \multicolumn{3}{|l|}{ Knowledge about HPV Vaccine } \\
\hline Yes & 10 & 11.8 \\
\hline No & 60 & 88.3 \\
\hline \multicolumn{3}{|l|}{$\underline{\text { Cervical cancer screening }}$} \\
\hline Yes & 5 & 5.9 \\
\hline No & 70 & 82.4 \\
\hline \multicolumn{3}{|l|}{ Breast Cancer Related Risk Factors } \\
\hline$\underline{\text { Miscarriage }}$ & $\underline{\text { Frequency }}$ & Percentage (\%) \\
\hline Yes & 20 & 23.5 \\
\hline No & 55 & 64.7 \\
\hline$\underline{\text { Abortion }}$ & $\underline{\text { Frequency }}$ & Percentage (\%) \\
\hline Yes & 5 & 5.9 \\
\hline No & 70 & 82.4 \\
\hline Use of contraceptives & Frequency & Percentage (\%) \\
\hline Yes & 30 & 35.3 \\
\hline No & 45 & 52.9 \\
\hline$\underline{\text { Lump present }}$ & Frequency & Percentage (\%) \\
\hline Yes & 25 & 29.4 \\
\hline No & 50 & 58.8 \\
\hline \multicolumn{3}{|l|}{ Lung Cancer Risk Factors } \\
\hline \multicolumn{3}{|l|}{ Smoking } \\
\hline Yes & 15 & 17.6 \\
\hline No & 70 & 82.4 \\
\hline \multicolumn{3}{|l|}{ Bronchitis/asthma/tuberculosis } \\
\hline Yes & 35 & 41.2 \\
\hline No & 50 & 58.8 \\
\hline
\end{tabular}


percent of women had used contraceptives. During the interview process, women volunteered additional information about their experiences with intimate partner violence. One of the female beneficiary complained pain after experiencing physical violation from her husband. All seventy-five women participants stated that being beaten by their husbands was a normal phenomenon.

Figure 1 shows menopausal age of the female participants. Ten (11.8\%) were menopausal and the average age of menopause was 43 years.

The prevalence of infectious disease was much higher than non-communicable diseases among Rohingya refugees (Figure 2). While fifteen (17.6\%) participants admitted to tobacco use, thirty-five (41.2\%) endorsed a history of asthma, bronchitis, and/or tuberculosis. The participants also noted that other family members were suffering from asthma and other lung diseases. Table 5 represents the pain presentation among the Rohingya participants. Thirty-five $(41.2 \%)$ people complained of overall body ache and fifteen (17.6\%) people presented with severe pain.

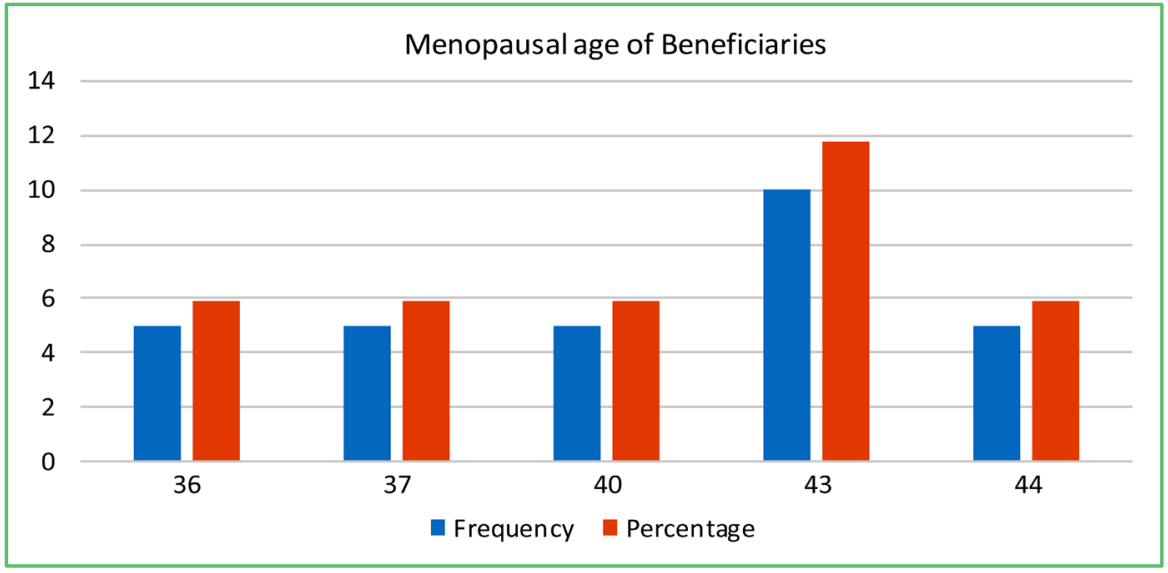

Figure 1. Menopausal age of the Rohingya Women Participants in the Kutupalong Refugee camp in Ukhiya, Cox's Bazar.

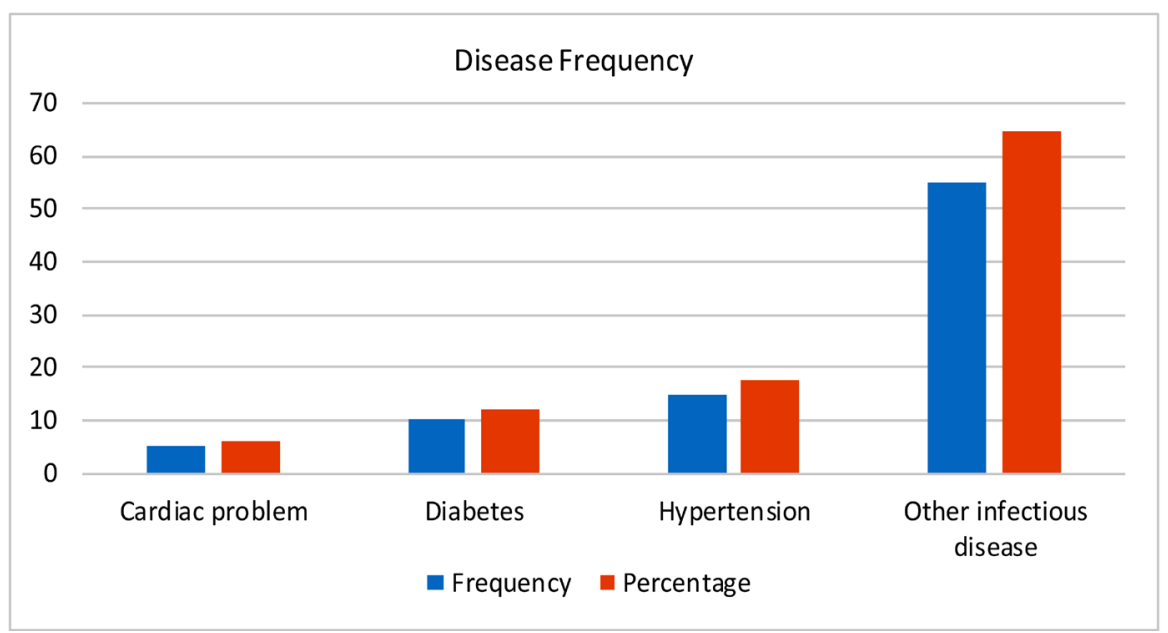

Figure 2. Disease frequency among the 85 Rohingya Participants in the Kutupalong Refugee camp in Ukhiya, Cox's Bazar. 
Table 5. Pain presentation and pain intensity of 85 Rohingya Participants in the Kutupalong Refugee camp in Ukhiya, Cox's Bazar.

\begin{tabular}{ccc}
\hline & Frequency & Percentage (\%) \\
\hline Pain present & 35 & 41.2 \\
Yes & 40 & 47.1 \\
No & & \\
Intensity & 10 & 11.8 \\
Mild & 10 & 11.8 \\
Moderate & 15 & 17.6 \\
Severe & 50 & 58.8 \\
None & & \\
\hline
\end{tabular}

\section{Interventions}

Educational sessions about cancer risks and signs and symptoms of oral, lung, breast, and cervical cancer were given after each interview. A training session on Self Breast Examination was done and the feedback was positive. After instruction and demonstration, the women participants could demonstrate how to do the examination.

\section{Discussion}

The Rohingya refugee population experienced a long and documented experience of deprivation in Myanmar that encompassed education, healthcare, and economic instability [13] [14]. The consequence of this systematic neglect of basic human rights has led to a population with little formal education, lack of preventative healthcare, and severe poverty. In the refugee camps of Bangladesh, $54 \%$ of the population is below the age of 18 [15].

The overall focus of the health sector in the Rohingya refugee camps is on emergency response, communicable diseases, maternal and child care, and community health [4]. Resources have improved in the registered Rohingya populations of the refugee camps. There is antenatal coverage for $94 \%$ of the population and close to $100 \%$ of births are attended by skilled birth attendants. However there is a scarcity with four trained doctors, four trained nurses, and trained sixteen community health workers per a population of 13,000 [16]. While 33,131 refugees are registered, another 80,000 undocumented refugees live in makeshift camps in the Cox's Bazar region. These undocumented refugees do not receive the same health benefits as those in the camps [17].

A 2018 rapid needs assessment of 1828 individuals in 402 Rohingya refugee households identified education, poverty, and access to healthcare as crucial needs [6]. The mean Rohingya household size was four people, with the average age of 20 years and with $51 \%$ being female. An average of $14 \%$ of Rohingya families reported difficulty accessing healthcare due to distances, finances, or other reasons and over $73 \%$ of pregnant women delivered at home without a certified birth attendant [6]. Both children and adolescent girls need nutritional support 
[15]. A cross-sectional study identified $24 \%$ of children from ages 6 months to 59 months with global acute malnutrition [18]. Language is an additional barrier to care [19]. Refugees also lack health literacy.

In the two major camps of Kutupalong and Nayapara, crude mortality rate per 1000 per month was 0.2 and 0.4 respectively [14]. Among a population of 913,316 Rohingya refugees in Cox's Bazar District, there were 135 mortalities in a 12-week period [4]. Twenty-six percent of these deaths were women of reproductive age, stillbirths, and neonatal deaths. The average age of female mortalities was 45.3 years and 35.5 years for male deaths. Seventy-six percent of deaths reported occurred at home. The actual cause of death was not known in $70 \%$ of cases. The crude death rate is of 14.7 over 3 months [20]. Overall, Rohingya households experienced 78 deaths in the preceding twelve months compared to 16 deaths among the host households [6].

Infectious and communicable diseases have been the leading cause of illness among the Rohingya refugees. Communicable diseases are an immediate concern and tuberculosis is a major concern. Myanmar was ranked among the top 30 countries for tuberculosis in 2016 [21]. Less than 61 percent of children less than age 2 years had received the nine recommended injectable vaccines and the four oral vaccines in Myanmar and less than $42 \%$ of children under age four had received any of these vaccines. Measles outbreaks occurred among new arrivals with a report of 419 cases [22]. 5800 cases of Diphtheria were reported in February 2018 [23]. Risks of communicable diseases were related to access to clean water and latrines. Water, sanitation and hygiene (WASH) services were reported to only reach $30 \%$ of the refugee population in 2018 [15].

Communicable diseases in Kutupalong and Nayapara camps ranged from $33 \%$ to $17 \%$ for upper respiratory tract infections; $11.6 \%$ to $17.9 \%$ for lower respiratory tract infections; $7 \%$ to $9 \%$ for diarrheal disease, and $11 \%$ to $12 \%$ for skin infections [14]. Non-communicable diseases are a concern such as chronic pulmonary disease from exposures to indoor cooking fires with poor ventilation and kidney and liver toxins from exposures to polluted waters.

Non-communicable respiratory disorders ranged from $30 \%$ to $47 \%$; endocrine disorders $30 \%$ to $21 \%$, and cardiovascular disease $19 \%$ to $15 \%$ respectively. Refugees suffered from treatment resistant tuberculosis (21\%), pain (73\%), insomnia (56\%), cough (55\%), anorexia (45\%), and dyspnea (39\%) [24].

Among the Rohingya refugees, severe physical disabilities from violence and injuries (63\%) are more common than cancer (10\%) [24]. 89.5\% of residents in Kutupalong and $64 \%$ of residents in Nayapara experience injuries from accidents [14].

Sexually transmitted infections are prevalent because of a high baseline rate in Myanmar, sexual assault of Rohingya women, and sexual exploitation of women in the refugee camps [25] [26].

One in seven Rohingya women in Northern Rakhine state had undergone at least one unskilled abortion in unhygienic conditions [27]. 
Life-limiting illness and mortality occur from the consequences of violence, malnutrition, maternal mortality, infectious diseases, non-communicable diseases and cancers. Disabilities increase in the setting of poverty, food insecurity, lack of employment and lack of education with an estimated 18\% of the Rohingya refugee population challenged by disability [16].

Preventable cancers include those that are sexually transmitted from human papilloma virus infections and environmentally induced cancers from pollutants and tobacco products. Other preventable cancers are those that can be detected early with appropriate screening such as skin cancers, breast, prostate, colon, and cervical cancers. Cervical cancer risk has a two-fold increased risk for women exposed to early sexual debut at ages 14 to 15 years and multiple sexual partners compared to women without those exposures [28]. Oral cancers are common in South Asia due to Betel nut and tobacco chewing and carry only a fifty percent survival [10].

Our rapid situational analysis of 85 people confirmed the findings of other investigators. We identified that cancer risk factors of lack of awareness, screening, poor hygiene and exposure to carcinogens are present in the Rohingya refugee community.

In our study $82.4 \%$ respondents were not familiar with the term lung cancer, only $29.4 \%$ knew about breast cancer, $11.8 \%$ understood the term cervical cancer, and $55.9 \%$ were familiar with the term oral cancer.

\section{Limitations}

Since we visited the camp for a really very short period of time, sample size may be insufficient to represent total FDMN Rohingya population.

\section{Conclusions and Recommendation}

Kutupalong is a refugee camp in Ukhiya, Cox's Bazar, Bangladesh inhabited by Rohingyas who fled from ethnic and religious persecution in neighboring Myanmar. Extreme poverty, lack of resources and poor health services are contributing factors towards acute and chronic diseases.

The Rohingya refugees lack knowledge about cancer risk factors, and cancer symptoms.

This community needs education about preventable cancers and its early symptoms. The session of Self Breast Examination (SBE) helped the participants to learn about screening. Most of the people are smokers and use betel nut with jorda, which is very harmful for lungs, and can also cause oral cancer. Interventions to reduce smoking and betel quid chewing are very important in the community. Forty-one percent of participants experienced pain. Pain relief and palliation of symptoms should be additional resources at the health facility.

\section{Acknowledgements}

We are very grateful to Refugee repartition rehabilitation commission for allow- 
ing us to do the short survey. We are also grateful to ACI conglomerate for supporting us with the survey.

\section{Funding}

This research did not receive any funding in the public, commercial, or not-forprofit sectors.

\section{Conflicts of Interest}

The authors declare that they have no competing interests.

\section{References}

[1] IOM International Organization for Migration (2017) Situation Report: Rohingya Refugee, Crisis Cox's Bazar. https://reliefweb.int/sites/reliefweb.int/files/resources/171126 weekly iscg sitrep fi nal.pdf

[2] Chan, E.Y.Y. and Murray, V. (2017) What Are the Health Research Needs for the Sendai Framework? The Lancet, 390, e35-e36. https://doi.org/10.1016/S0140-6736(17)31670-7

[3] Chan, E.Y., Chiu, C.P. and Chan, G.K. (2018) Medical and Health Risks Associated with Communicable Diseases of Rohingya Refugees in Bangladesh 2017. International Journal of Infectious Diseases, 68, 39-43. https://doi.org/10.1016/j.ijid.2018.01.001

[4] OCHA (2019) Humanitarian Response Health Sector Cox's Bazar: Rohingya Crisis in Cox's Bazar District. Health Sector Bulletin Number 10, Bangladesh. https://www.humanitarianresponse.info/en/operations/bangladesh/document/healt $\underline{\text { h-sector-bulletin-no5 }}$

[5] Ahmad, M.S. and Rahman, N. (2019) Emergency Response Training and Provision of Emergency Response Kits to Rohingya Community Leaders: An Approach to Local Disaster Risk Reduction and Community Resilience. Emergency Medicine Journal, 36, 255-256. https://doi.org/10.1136/emermed-2018-207843

[6] Bhatia, A., Mahmud, A., Fuller, A., Shin, R., Rahman, A., Shatil, T., Sultana, M., Morshed, K.M. and Balsari, S. (2018) The Rohingya in Cox's Bazar: When the Stateless Seek Refuge. Health and Human Rights, 20, 105-122.

[7] Tay, A.K., Riley, A., Islam, R., Welton-Mitchell, C., Duchesne, B., Waters, V., Varner, A., Moussa, B., Mahmudul Alam, A.N.M., Elshazly, M.A., Silove, D. and Ventevogel, P. (2019) The Culture, Mental Health and Psychosocial Wellbeing of Rohingya Refugees: A Systematic Review. Epidemiology and Psychiatric Sciences, 28, 489-494. https://doi.org/10.1017/S2045796019000192

[8] McCaffery, M. and Beebe, A. (1989) The Numeric Pain Rating Scale Instructions. In: McCaffery, M. and Beebe, A., Eds., Pain: Clinic Manual for Nursing Practice, Mosby, St. Louis, 769.

[9] Jitender, S., Sarika, G., Varada, H.R., Omprakash, Y. and Mohsin, K. (2016) Screening for Oral Cancer. Journal of Experimental Therapeutics and Oncology, 11, 303-307.

[10] Kumar, M., Nanavati, R., Modi, T.G. and Dobariya, C. (2016) Oral Cancer: Etiology and Risk Factors: A Review. Journal of Cancer Research and Therapeutics, 12, 458. https://doi.org/10.4103/0973-1482.186696

[11] Malhotra, J., Malvezzi, M., Negri, E., La Vecchia, C. and Boffetta, P. (2016) Risk 
Factors for Lung Cancer Worldwide. European Respiratory Journal, 48, 889-902. https://doi.org/10.1183/13993003.00359-2016

[12] Ames, H., Glenton, C. and Lewin, S. (2019) Purposive Sampling in a Qualitative Evidence Synthesis: A Worked Example from a Synthesis on Parental Perceptions of Vaccination Communication. BMC Medical Research Methodology, 19, 26. https://doi.org/10.1186/s12874-019-0665-4

[13] Coutts, E. (2005) The Rohingya Refugee Situation in Bangladesh. American Internal School, Dhaka. https://www.rna-press.com/data/itemfiles/9bcc51b07210277172cfaca50dd60ff6.pdf

[14] Milton, A.H., Rahman, M., Hussain, S., Jindal, C., Choudhury, S., Akter, S., Efird, J.T., et al. (2017) Trapped in Statelessness: Rohingya Refugees in Bangladesh. International Journal of Environmental Research and Public Health, 14, 942. https://doi.org/10.3390/ijerph14080942

[15] Islam, M.M. and Nuzhath, T. (2018) Health Risks of Rohingya Refugee Population in Bangladesh: A Call for Global Attention. Journal of Global Health, 8, Article ID: 020309. https://doi.org/10.7189/jogh.08.020309

[16] Landry, M.D. and Tupetz, A. (2018) Disability and the Rohingya Displacement Crisis: A Humanitarian Priority. Archives of Physical Medicine and Rehabilitation, 99, 2122-2124. https://doi.org/10.1016/j.apmr.2018.06.005

[17] White, K. (2017) Rohingya in Bangladesh: An Unfolding Public Health Emergency. The Lancet, 390, 1947. https://doi.org/10.1016/S0140-6736(17)32677-6

[18] Leidman, E., Humphreys, A., Greene Cramer, B., Toroitich-Van Mil, L., Wilkinson, C., Narayan, A. and Bilukha, O. (2018) Acute Malnutrition and Anemia among Rohingya Children in Kutupalong Camp, Bangladesh. JAMA, 319, 1505-1506. https://doi.org/10.1001/jama.2018.2405

[19] Jiwrajka, M., Mahmoud, A. and Uppal, M. (2017) A Rohingya Refugee's Journey in Australia and the Barriers to Accessing Healthcare. BMJ Case Reports, 2017, bcr2017219674. https://doi.org/10.1136/bcr-2017-219674

[20] Parmar, P.K., Jin, R.O., Walsh, M. and Scott, J. (2019) Mortality in Rohingya Refugee Camps in Bangladesh: Historical, Social, and Political Context. Sexual and Reproductive Health Matters, 27, Article ID: 1610275. https://doi.org/10.1080/26410397.2019.1610275

[21] WHO World Health Organization (2017) Global Tuberculosis Report. http://apps.who.int/iris/bitstream/10665/259366/1/9789241565516-eng.pdf?ua=1

[22] UNICEF (2017) United Nations Children's Fund. Bangladesh Humanitarian Situation Report-10 (Rohingya Influx), New York. https://www.unicef.org/about/annualreport/files/Bangladesh 2017 COAR.pdf

[23] Rahman, M.R. and Islam, K. (2019) Massive Diphtheria Outbreak among Rohingya Refugees: Lessons Learnt. Journal of Travel Medicine, 26, tay122.

https://doi.org/10.1093/jtm/tay122

[24] Doherty, M. and Khan, F. (1993) Palliative Care during a Humanitarian Crisis: Experience from the Rohingya Refugee Camps in Bangladesh. Journal of Pain and Symptom Management, 56, e28-e29.

https://doi.org/10.1016/j.jpainsymman.2018.10.024

[25] Hossain, M.M., Sultana, A. and Das, A. (2018) Gender-Based Violence among Rohingya Refugees in Bangladesh: A Public Health Challenge. Indian Journal of Medical Ethics, 1-2. https://doi.org/10.20529/IJME.2018.045

[26] Hossain, M.M., Sultana, A. and Mazumder, H. (2018) Sexually Transmitted Infec- 
tions among Rohingya Refugees in Bangladesh. The Lancet HIV, 5, e342. https://doi.org/10.1016/S2352-3018(18)30140-1

[27] Mahmood, S.S., Wroe, E., Fuller, A. and Leaning, J. (2017) The Rohingya People of Myanmar: Health, Human Rights, and Identity. The Lancet, 389, 1841-1850. https://doi.org/10.1016/S0140-6736(16)00646-2

[28] Herrero, R., Brinton, L.A., Reeves, W.C., Brenes, M.M., Tenorio, F., de Britton, R.C., Gaitan, E., Garcia, M. and Rawls, W.E. (1990) Sexual Behavior, Venereal Diseases, Hygiene Practices, and Invasive Cervical Cancer in a High-Risk Population. Cancer, 65, 380-386.

https://doi.org/10.1002/1097-0142(19900115)65:2<380::AID-CNCR2820650234>3.0 .CO;2-9 